40

SC-RR - 68-35I

May 1968

815

DESIGN OF SPACE NUCLEAR POWER SUPPLIES FOR INTACT REENTRY

\section{2}

AEROSPACE NUCLEAR

SAFETY
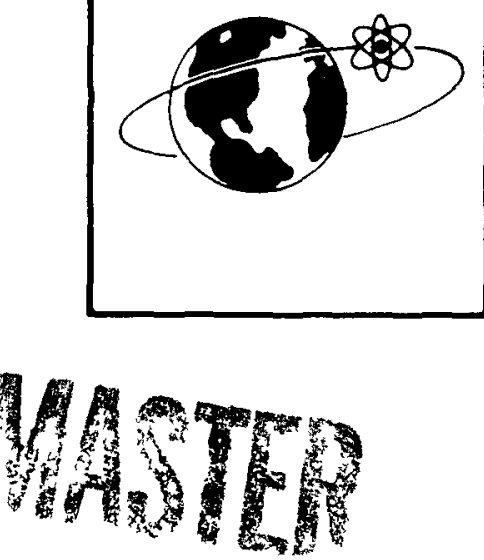

R. D. Klett, 9314 


\section{DISCLAIMER}

This report was prepared as an account of work sponsored by an agency of the United States Government. Neither the United States Government nor any agency Thereof, nor any of their employees, makes any warranty, express or implied, or assumes any legal liability or responsibility for the accuracy, completeness, or usefulness of any information, apparatus, product, or process disclosed, or represents that its use would not infringe privately owned rights. Reference herein to any specific commercial product, process, or service by trade name, trademark, manufacturer, or otherwise does not necessarily constitute or imply its endorsement, recommendation, or favoring by the United States Government or any agency thereof. The views and opinions of authors expressed herein do not necessarily state or reflect those of the United States Government or any agency thereof. 


\section{DISCLAIMER}

Portions of this document may be illegible in electronic image products. Images are produced from the best available original document. 
Is sued by Sandia Corporation

a prime contractor to the

United States Atomic Energy Commission

\section{LEGAL NOTICE}

Thes repart was prepared as on account of Government sponsored work. Net ther the United States, nor the Cammission, nor any person acting on behalf of the Commission

A. Makes ony warronty or representation, expressed or implied, with respect to the occuracy, completeness, or usefulness of the information contaned in this report, or that the use of any information, apporatus, method, or process disclosed in this report moy not infringe privately owned rights or

B. Assumes any liabilities with respect to the use of or for damages resulting from the use of any information, opparatus, method, or process disclosed in this report.

As used in the above, "person acting on behalf of the Commission" includes any employee or contractor of the Commission, or emplayee of such contractor, to the extent that such employee or contractor of the Commission, or employee of such controctor prepares, disseminates, or provides access to, any information pursuant to his emplayment or contract with the Commission, or his employment with such contractor.

\section{Printed in the United States of America Available from \\ Clearinghouse for Federal Scientific and Technical Information National Bureau of Standards, U. S. Department of Commerce Springfield, Virginia 22151 \\ Price: Printed Copy $\$ 3.00$; Microfiche $\$ 0.65$}



of any informatlon, apparatus, method, or process diaclosed in thes report mayy not infringe privarely aumed righter or

a

As uned in the above. "perac

ployee or contractor of the commiselion, or enployee of such contractor, to the extent that auch employee or contractor of the Commission, or employee of such contractor prepare

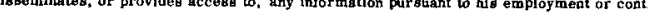

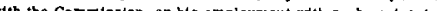

SC-RR- $68-351$

DESIGN OF SPACE NUCLEAR POWER

SUPPLIES FOR INTACT REENTRY

R. D. Klett, 9314

Sandia Laboratory, Albuquerque

Approved By:

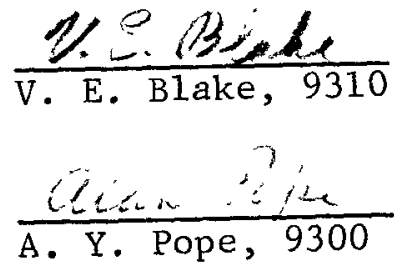

ABSTRACT

This report describes the environments which have an adverse effect on intact reentry of space nuclear power supplies and the effects each environment has on the design. Some basic intact design concepts are suggested. Parametric thermal studies for early phases of a design are discussed.

May 1968 
Blank Page 
As part of the Aerospace Nuclear Safety Program, Sandia Corporation develops guidelines and techniques that will aid in the design of safe nuclear power supplies. It was found that it is safer to contain some fuel forms throughout reentry rather than attempt to disperse the fuel at high altitudes. The environments that intact nuclear power supplies are exposed to are discussed in this report. The requirements each environment places on the design are covered, and basic design concepts are suggested.

Parametric time saving methods are presented for analysis of some early phases of power supply thermal design. 
Blank Page 


\title{
DESIGN OF SPACE NUCLEAR POWER SUPPLIES FOR INTACT REENTRY
}

\author{
Introduction
}

The reentry safety of early space nuclear power supplies was based on high altitude melting or dispersal of the fuel. The fuel would eventually settle to earth over a large area, and the fuel particles would be of a size which would not constitute a health hazard. However, it was found that under certain reentry conditions the fuel could reach the earth in undesirable particle sizes and distributions.1,2 As an alternate approach to safe reentry of nuclear power supplies, several of the later fuel capsules were designed to reenter intact for all probable trajectories associated with their missions. If the fuel reenters without melting and is contained down to earth impact, the particle size can be controlled and the fuel will be confined to a small area. Another category of intact reentry requires fuel containment after earth impact. If the fuel can be contained after earth impact, there is a possibility of recovering expensive fuel as well as increasing safety. The third category of intact reentry is intact with burial. The object of burial is to cover the fuel with enough soil to form a nuclear radiation shield. The relative merits and safety of each type of intact reentry are not discussed in this report. The environments the intact generator must survive are discussed along with the basic design concepts of intact nuclear generators. More general intact design concepts appear in Reference 3 and were applied to the intact version of the SNAP-19. All thermal analyses of the intact version of the SNAP-19 show that it will survive reentry with an ample safety margin.

In the design of intact reentry systems with internal heat sources, it is necessary to achieve the proper amount of internal thermal resistance to protect against aerodynamic heating during reentry and to allow the internally generated heat to be rejected during operation without exceeding maximum permissible capsule temperatures. The internal resistance can easily be analyzed using parametric methods described in this report.

\section{Design Considerations for Intact Reentry}

This section discusses the environments that are inimical to the intact reentry of space nuclear power supplies. The effects these environments have on the design of power supplies are discussed, and methods to cope with each environment are proposed. All of the environments are not necessarily associated with every reentry system and every trajectory, but any one could cause failure of an improperly designed generator. The designs suggested are merely guidelines. They are not necessarily the optimum designs, nor are they necessarily applicable to a11 power supplies or missions. 


\section{Internal Pressure}

At the operating temperatures currently being used in SNAP systems, part of the helium generated by the radioactive decay of isotopic fuels is released; the remainder is stored in the fuel. If the fuel capsule is not vented, the released helium will cause the internal pressure to increase (Figure 1). If the generator is put in a longlife orbit, the internal pressure could cause the generator to rupture before it begins reentry. For shorter duration, elliptical orbits, the capsules might not rupture prior to reentry, but the time from manufacture to reentry could be sufficient to increase the internal pressure significantly. The high temperatures the generator experiences during reentry will further increase the pressure and decrease the strength, possibly causing rupture during reentry. For some probes and preorbital aborts, the initial pressure and reentry temperatures may not be high enough to rupture the generator; however, the pressure will continue to increase and will eventually result in local fuel release if the generator is not recovered. Therefore, it is concluded that any generator designed for fuel containment after reentry must have either a vented fuel container or a large internal void volume. When there are multiple containers, several layers may have to be either vented or permeable to helium. Filters are needed over ports to prevent the escape of fuel particles.

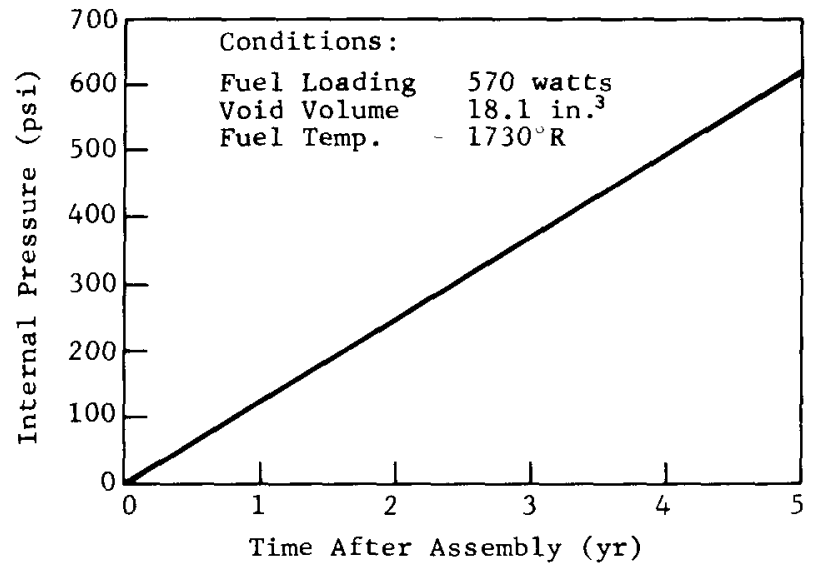

Figure 1 .

Typical pressure buildup in an unvented fuel capsule

$(D 68-11444)$

The problem is further complicated by the rapid release of the stored helium when the fuel temperature is increased during reentry. The helium released at operating temperature is liberated at a very low rate and can be expelled through a low leak rate porus plug. However, the stored helium (which amounts to from 25 to 50 percent of the total helium generated) is released in a matter of minutes. Figure 2, which was compiled from data in Reference 4, shows the pressure buildup during an orbital reentry versus temperature for one type of fuel capsule. The amount of helium stored in the fuel was based on reentry 2 years after manufacture. It was assumed that the capsule had a low flow rate filter that would pass all the helium generated at operating temperature but would not accommodate the helium released during reentry. 


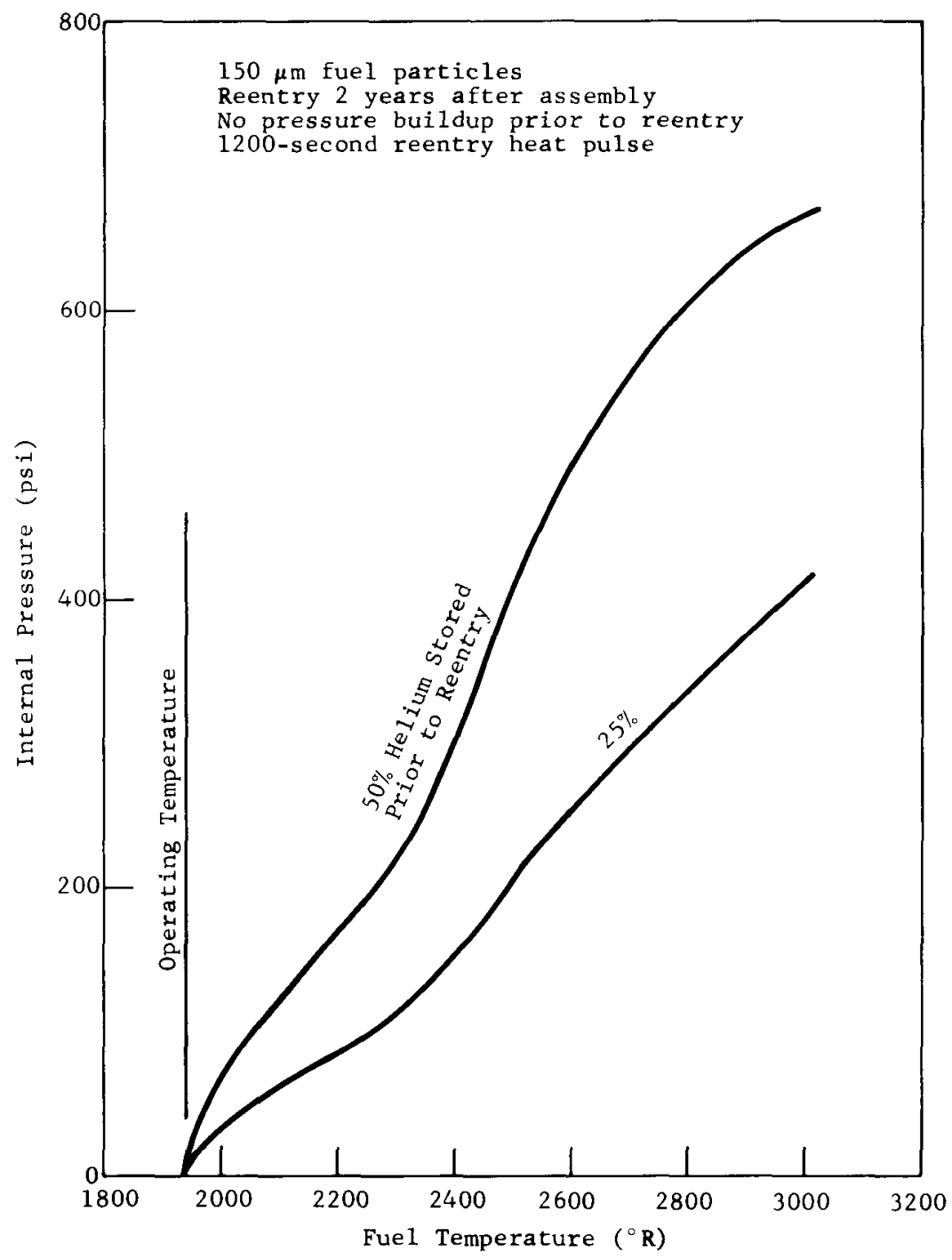

Figure 2. Fuel capsule pressure buildup during reentry caused by release of helium stored in the fuel (D68-11445)

A small particle fuel form that stores helium and then releases it at elevated temperatures creates a serious design problem for an intact system. The fuel container must have high flow rate vents with filters to contain the fuel and yet be able to withstand reentry heating.

\section{Thermal Stresses}

Thermal stresses can be separated into those caused by the relative thermal expansion of different materials and those caused by large temperature gradients in brittle structures. Relative thermal expansion 
becomes a problem during reentry when the coefficient of thermal expansion of an outer structure is lower than that of an inner structure. The capsule must be held rigid at operating temperatures to prevent launch vibration damage and to keep the capsule centered for uniform heat transfer. There are several rigid mounts which permit the inner structure to expand more than the outer structure during reentry without causing high stresses. The cantilevered capsule used in the SNAP -27, the refractory felt compliance members used on the ends of the intact SNAP-19, and the support shown in Figure 3 will be rigid during both heating and cooling. The cantilever design requires some means of expansion compensation on the attachment end and an additional support on the other end of long capsules. It also depends on radiation and conduction through gas to transfer heat from the capsule. The support in Figure 3 is most rigid and easiest to manufacture and assemble but requires that the reentry heating of the generator be nearly uniform. The use of a compliance member offers the most advantages for the majority of cylindrical and spherical generator designs. It is recommended that the compliance member completely enclose the capsule (Figure 4). Surrounding the capsule distributes the loads more evenly, and the lower stress in the compliance member reduces the restrictions on material selection. One of the most important features of the compliance member support is the conduction path it offers even if the generator is punctured and pressure is lost. With some generator configurations, this additional conduction path could prevent capsule melting prior to reentry. The capsule could be inserted by placing a removable shim stock sleeve between the side compliance members and the capsule. Metal liners between the ablation material end caps and the end compliance members will also facilitate assembly. End plugs in a cylindrical heat shield would facilitate assembly as we 11 as simplify manufacture, increase strength, and maximize the usable thickness of the ablation material.

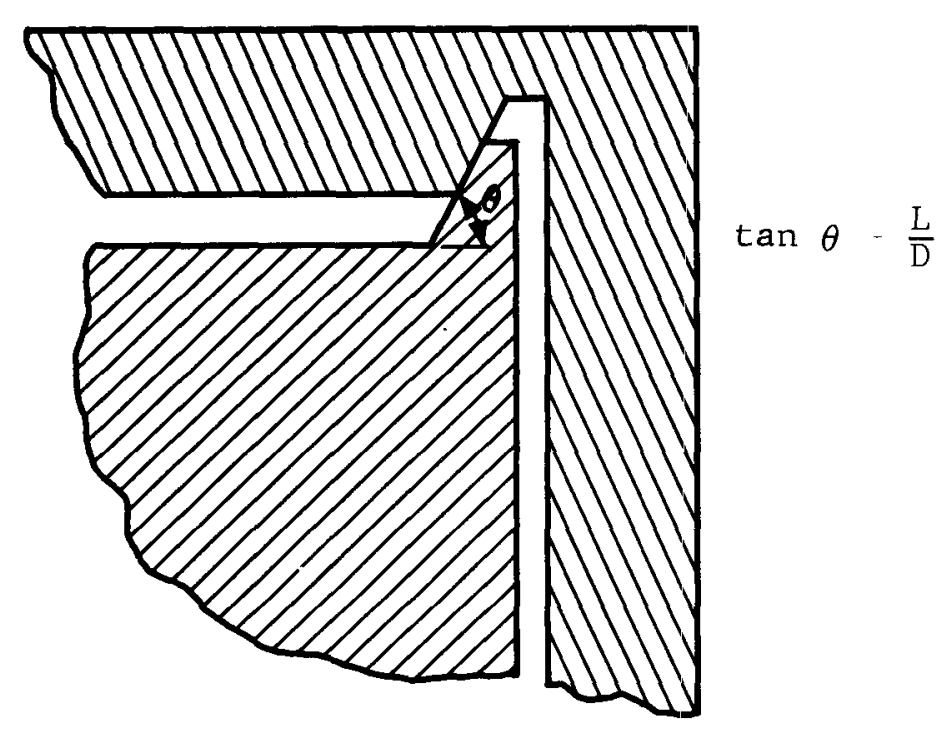

Figure 3. Rigid support for coaxial cylinders with unequal coefficients of thermal expansion (D68-11.446) 


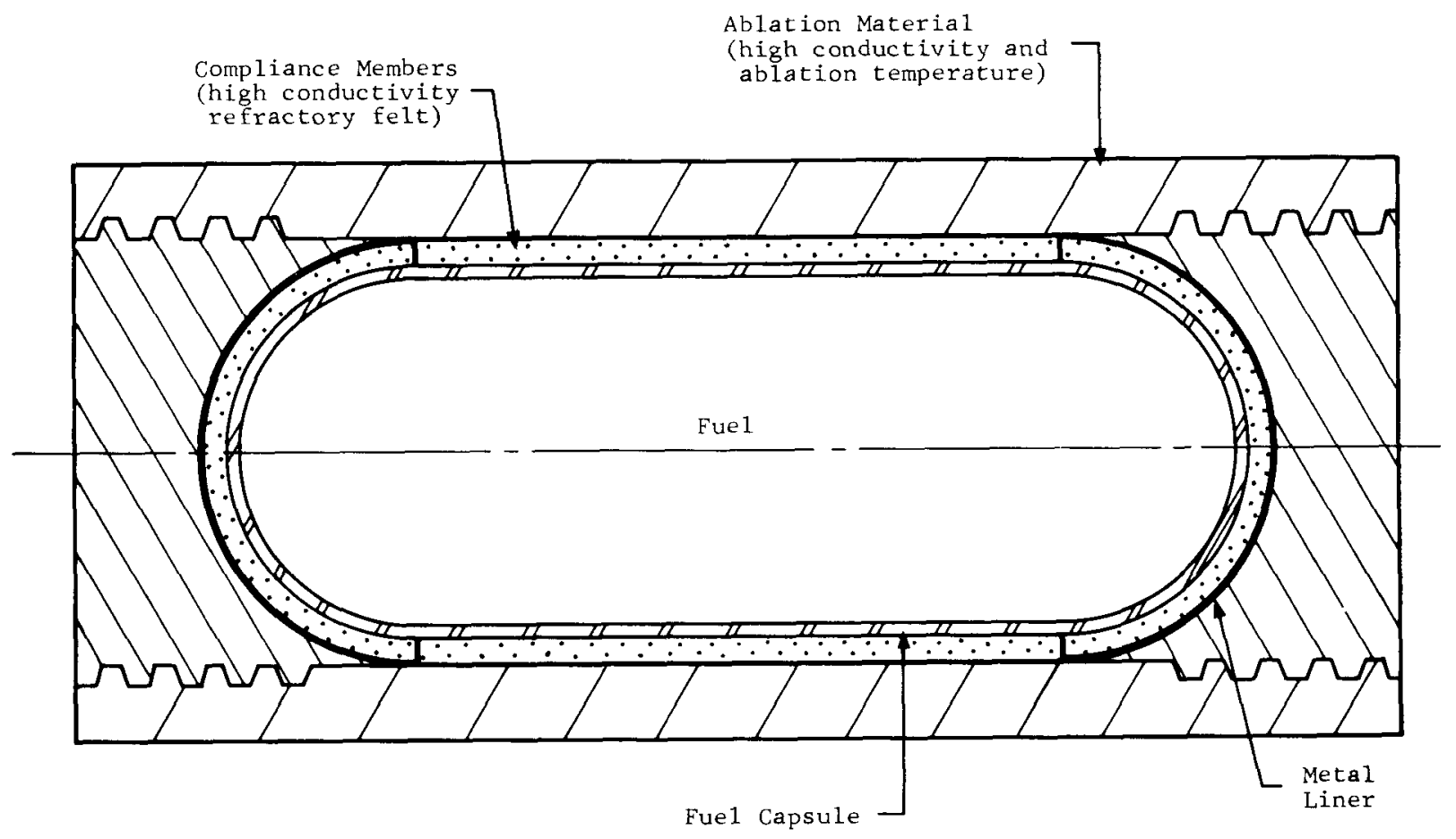

Figure 4. Compliance member support $(D 68-11447)$

Another simple support is the crushable o-ring (Figure 5). The o-ring holds the capsule rigidly until after peak reentry heating. A gap forms when the capsule cools, but this does not create a problem. Placing the o-ring inboard of a lip in the capsule does not require removal of the heat shield material in the critical corner area, and the o-ring merely has to deform during expansion rather than crush as it would if it were in the corner. The ideal material for the o-ring would have high strength at operating temperature, low strength above operating temperature, and a melting temperature below that of the capsule. Figure 6 shows the yield strengths and melting temperatures of some of the materials best suited for this application.

These are only a few of the possible methods of expansion compensation. Depending on the configuration, several of the standard methods, such as springs, elastic members, matched or compensating coefficients of thermal expansion, etc., can be used.

High thermal stresses in a single material can be caused by uniform, high heating rates. These stresses can result in either spalling of the surface or total failure of the capsule. The use of elastomeric material, high conductivity material, and/or thin structures can reduce these stresses to an acceptable level. High local heating rates may also cause excessive thermal stresses. Hot spots result from stable orientation of the generator, shock-wave boundary layer interactions, flow reattachment, or corner flow. High local heating rates car be reduced by separating the generator cleanly from the spacecraft or by locating it in a protected area of the spacecraft. After the 


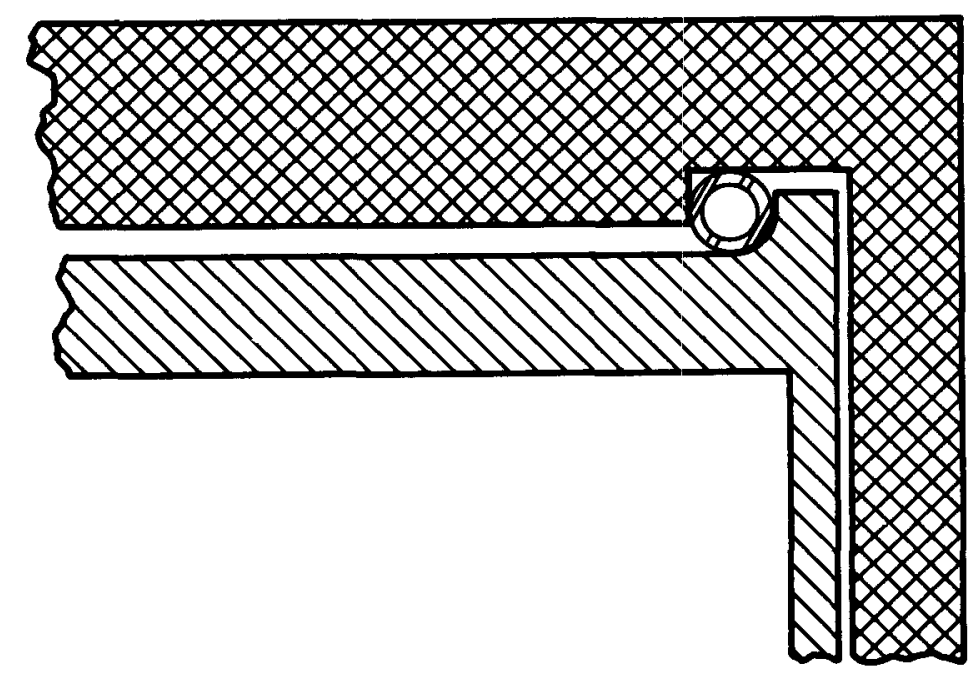

Figure 5. 0-ring support

(D68-11448)

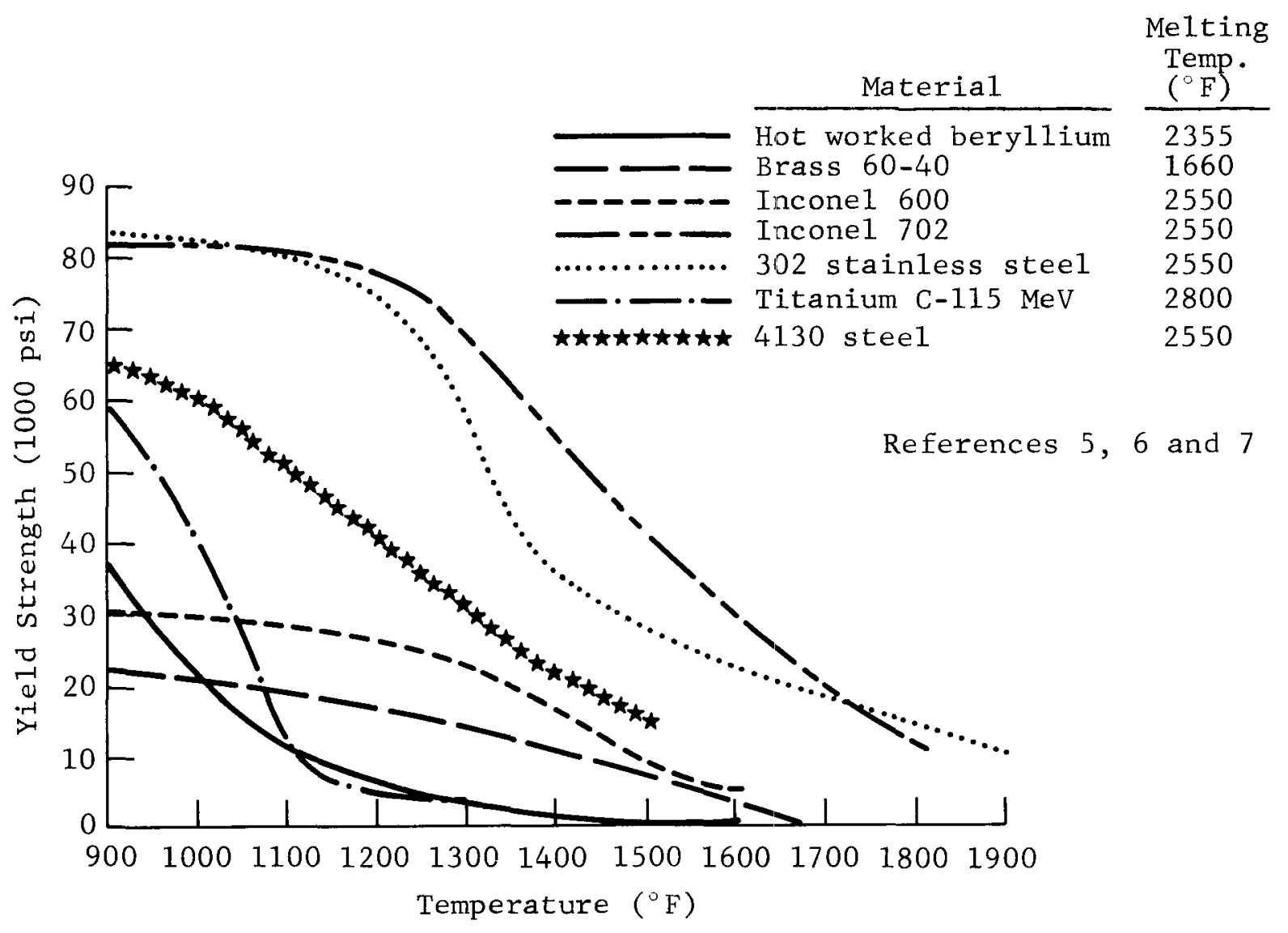

Figure 6. Yield strength of materials for o-ring support (D68-11449) 
generator is released from the spacecraft, it should either tumble to distribute the heat evenly or orient itself to protect the vulnerable areas. Al1 parts of the generator which are exposed to aeroheating and are used as thermal protection should be smooth to reduce local heating. It is desirable to prevent the melting of any interior parts of the generator. Liquids could collect in one location in the generator and produce an undesirable fixed flight attitude.

\section{Reentry Heating}

The high heating rates of reentry will cause at least partial disassembly of a generator by melting, sublimation, ablation, and oxidation. Complete destruction of the generator can be prevented by the following.

1. Designing the generator with as low a ballistic coefficient and as large a diameter as possible to reduce the amount of aerodynamic convective heating. Ballistic coefficients can be reduced by using small multiple containers, large void volumes, and high drag shapes. Radiation heating increases with the diameter of the vehicle, but radiation heating is negligible except for superorbital velocity lunar and planetary returns.

2. Using ablation material to protect high heating areas. The heat blockage efficiency of ablation materials increases with air enthalpy (high velocity). High strength ablation materials are needed for high velocity and large reentry angle trajectories, while low conductivity materials are needed for orbital decay trajectories.

3. Using a high emissivity material or coating to reject heat from outer surfaces by radiation. This method is most useful for long duration, low heating rate reentries such as orbital decay. The use of high temperature surfaces which are insulated from the inner part of the generator greatly increases the radiation losses. During orbital reentry, up to 80 percent of the net aeroheating before peak heating is reradiated. Shortly after peak heating, radiation losses exceed reentry heating.

4. Covering exterior surfaces with oxidation-resistant coatings.

5. Using a low fuel loading per unit surface area of the heat shield whenever allowed by the volumetric restrictions and generator design. The low fuel loading permits more insulation between the capsule and outer surface without exceeding permissible operating temperatures. The added insulation will protect the capsule from reentry heating.

6. When the thermal protection is uniform over the capsule surface, a tumbling/spinning motion is desirable during reentry to distribute the heat evenly. 
7. It may be possible to package the fuel capsules of large heat sources in a reentry vehicle without an excessive weight penalty. High heating areas of stable vehicles could be protected by ablation material. Heat generated by the fuel capsules during reentry could be rejected by low heating separated flow regions on the sides (Figure 7) or back (Figure 8) of the vehicle. The reentry vehicle configuration and the location selected for heat rejection are influenced by the design of the conversion unit, heat pipe, or heat exchanger. The major problems of this approach are: stabilizing the vehicle early in the reentry trajectory to prevent high heating rates to vulnerable areas, and protecting the high heating areas. Stabilizing devices are generally high heating areas. With the exception of stabilizing shear and pressure forces on the noses of some vehicles, stability is obtained by using flares, fins, etc., on the aft end of the vehicle. Adding ablation material to the aft end of the vehicle in turn reduces the stability. It is difficult to find an efficient ablation material for missions that may reenter on either a short duration, high heating rate trajectory, or on a long duration, low heating rate trajectory (see 2 above).

8. Whenever possible, it is desirable to utilize functional parts of the generator for thermal protection during reentry.

9. If fuel containment is not required after earth impact, the fuel capsule can be allowed to melt during reentry provided the fuel remains in the heat shield throughout the aero heat pulse. However, if fuel containment after earth impact is a requirement, the capsule must not fail during reentry. If net aero heating cannot be reduced sufficiently to permit intact reentry of superalloy fuel capsules, it may be necessary to use refractory metal capsules. The use of refractory capsules will permit higher surface temperatures which will radiate more of the incoming heat. Refractory capsules also need less insulation between the outer surface of the vehicle and the capsule during reentry. The reduced internal thermal resistance will result in more rapid cooling of the capsule and lower impact temperatures.

Fragment Damage

Explosive aborts, reentry debris, and meteors could rupture the generator or damage protective coatings. Multilayer construction of the generator and shielding of the generator by the spacecraft would afford a limited amount of protection. 


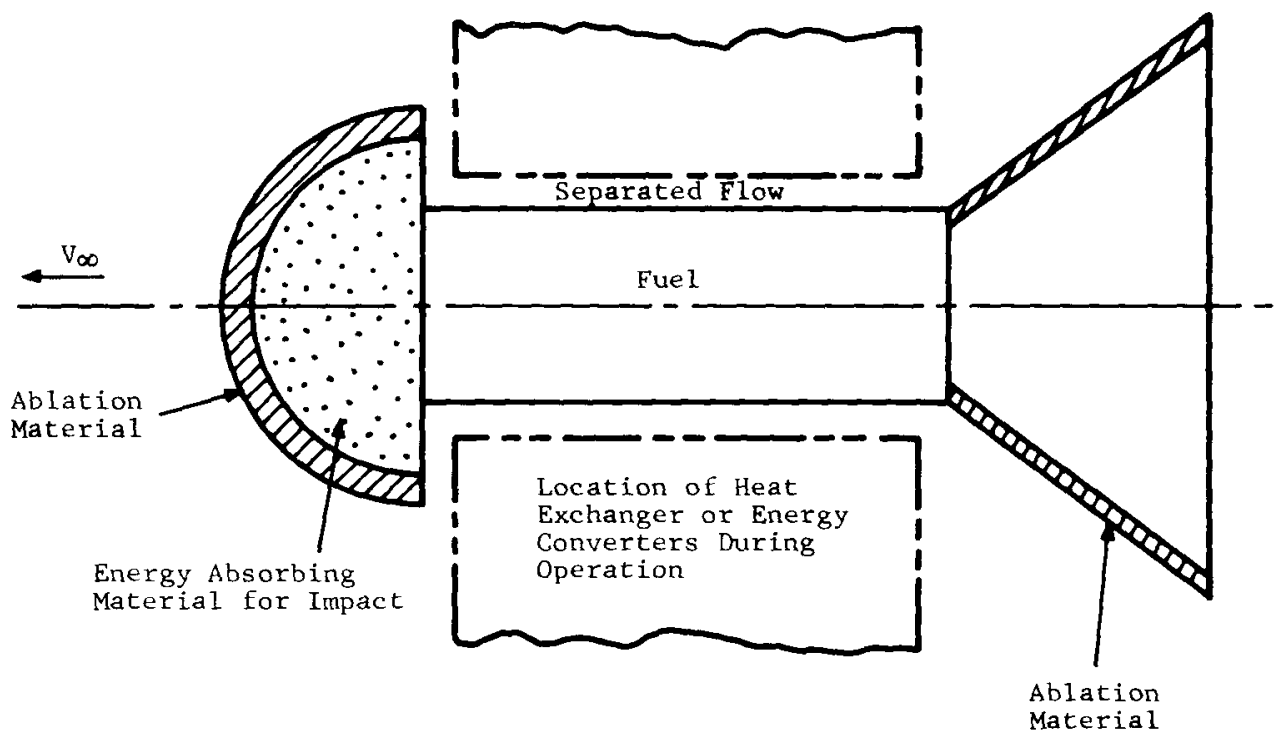

Figure 7. Stable fuel capsule/reentry vehicle for cylindrical heat exchanger (D68-11450)

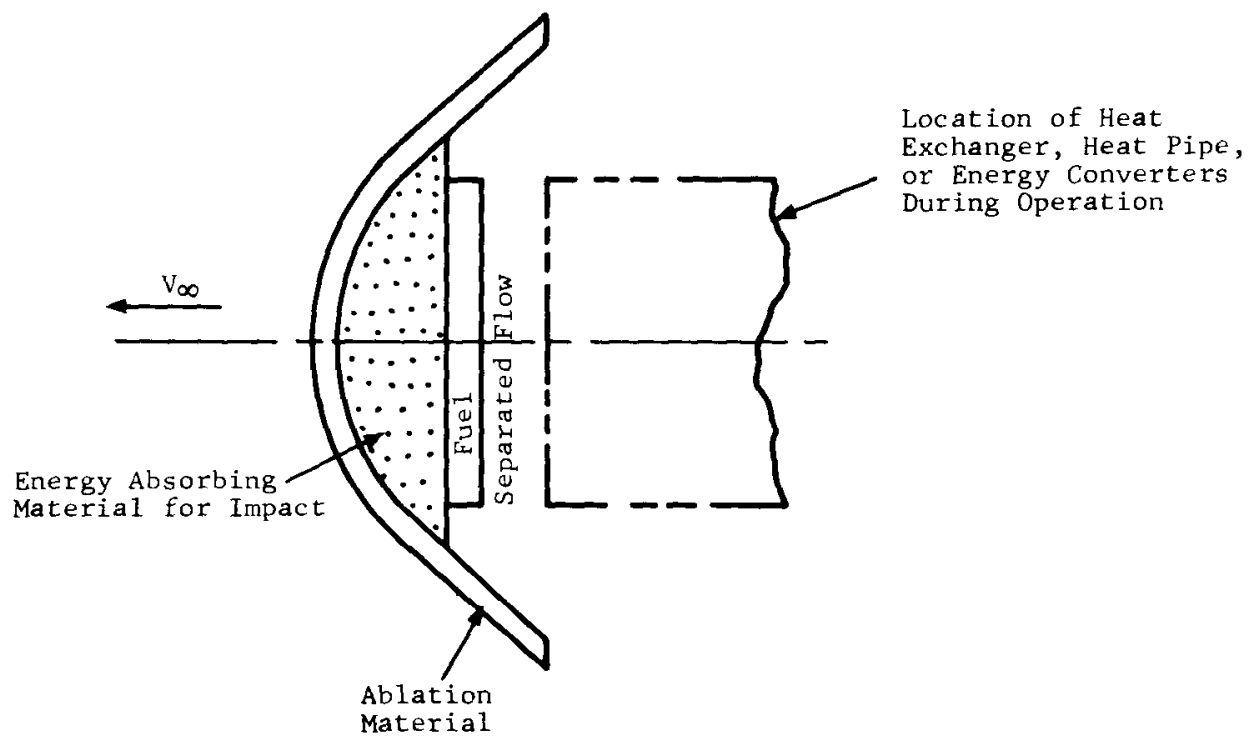

Figure 8. Stable fuel container/reentry vehicle for flat heat exchanger (D68-11451) 


\section{Abort Fires}

Launch pad abort fires are characterized by a high temperature fireball lasting several seconds, followed by a lower temperature residual fire lasting for many minutes.8 The initial firebal1 temperature is higher than the melting temperatures of any existing generator. Since heat is being transferred inward when the generator is in the fireba11, the generator must have a heat capacity high enough to absorb this heat. It is shown in Reference 9 that loss of the outer part of the generator prior to propellant ignition could reduce the heat capacity enough to cause melting of a fuel container before the fireball lifts.

During the long duration residual fire, heat must be transferred out of the generator or the generator will melt because of its own heat generation. Since the residual fire temperature is approximately $2300^{\circ} \mathrm{R}$, there must be a minimum thermal resistance between the fuel capsule and the generator surface to prevent most capsule materials from melting.

Generator cases made of low melting temperature materials such as magnesium can melt in the fireball in about 2 seconds. It would be more desirable to have a generator that would stay intact long enough to help absorb the impact loads if the generator falls to the launch pad. The thermal environments of explosive aborts after launch are not repeatable and have not been we1l defined.

\section{Chemica1 Reactions}

Some internal parts of the generator may melt during reentry, or after impact if the capsule is buried in low conductivity soil. Chemical reactions between the molten material or the fuel and the container could cause a failure with fuel release. These reactions can be prevented by selecting compatible materials, coating the containers with inert materials, using liners between materials that react, and using materials with high melting temperatures. The high melting temperature refractory metals oxidize at a high rate at temperatures well below their melt temperatures. Whenever a refractory metal is exposed to air either before launch, during reentry, or after earth impact, oxidation can be prevented or retarded by the use of coating. Oxidation-resistant coatings for several refractory metals can be found in References 10 and 11. Liners act as thermal radiation shields which increase internal temperature when heat is flowing outward. As shown in the Parametric Studies section, multiple radiation shields or a single radiation shield with low emissivity could cause melting of some capsules before reentry if internal pressure is lost and heat transfer across gaps is limited to radiation.

During operation of the generator, both long duration high temperatures and nuclear and solar radiation can degrade coating and material. Proper material selection and isolation of some components can eliminate or reduce this problem. 
Aerodynamic Forces

Tumbling or spinning motions during reentry are desirable for many capsule designs because aeroheating is distributed more evenly over the surface. However, if tumbling or spinning rates are too high, the centrifugal force could cause capsule failure. Whenever rotation inducing devices are incorporated in a generator design, tests should be conducted to determine maximum rotation rates. Deceleration forces are less than $10 \mathrm{~g}$ during orbital reentry, but higher deceleration loads can cause structural problems during supercircular reentries at steep reentry angles.

\section{Earth Impact}

The three types of intact reentry discussed in the Introduction each have different impact requirements. If fuel containment is required only until the reentry heat pulse is over, there are no impact requirements.

If complete fuel containment is required, the capsule must withstand earth impact and the environments on or under the earth or under water. A spacecraft and a generator with low ballistic coefficients greatly improve the chances of withstanding earth impact. Vehicles with lower ballistic coefficients impact at lower velocities, which reduces loads and burial depth. The lower heating rates, lower temperatures, and longer cooling times before impact of low ballistic coefficient vehicles result in cooler and stronger vehicles at impact. With lower heating rates, more of the generator survives reentry to act as an energy absorbing cushion at impact. Capsule materials with high strain rate ductility are essential when hard surfaces are impacted. If oxidation-resistant coatings are removed or scratched during impact, chemical failures could occur if the fuel is not recovered. Burial of the fuel capsule should be prevented to facilitate recovery and to reduce the probability of melting the capsule in soils having low thermal conductivity. If burial cannot be prevented, the heat should be dissipated by the use of low power density or small multiple fuel containers having high surface area to volume ratios.

Many of the requirements for intact reentry with burial are the opposite of those given above. The ballistic coefficient and velocity must be high, and the capsule must be stable with a small frontal area so it will penetrate. These requirements increase and localize reentry heating rates. A capsule design similar to those shown in Figures 7 and 8 with an ablative nose and separated flow over the sides or aft areas appears to be one of the most promising. When burial is required, the impact loads are more severe than with a nonburial system, and the capsule must be reinforced accordingly. Burial in solid rock is probably not practical. The problem of the capsule melting in low conductivity soil is the same as for a nonburial system, except multiple small capsules with low ballistic coefficients cannot be used.

It is obvious that the categories mentioned above are interrelated, and some have conflicting requirements. In these cases a compromise may be necessary unless one of the requirements can be relaxed. As an example, a high fuel emissivity is desirable during operation of a generator, in a shipping cask, in a launch pad abort residual fire, and 
during reentry of bare unprotected fuel. However, the same high fuel emissivity could cause melting of the fuel in a launch pad abort fireball or melting of encapsulated fuel during reentry.

A11 of the above suggestions are for a passive system. If active devices such as movable heat shields, stabilizing rockets, or parachutes can be employed with high reliability, the problems of designing intact power supplies would be simplified.

\section{Parametric Studies}

Two techniques are presented in this section to aid in thermal analyses during early phases of space nuclear power supply design. The first is a method of finding the approximate surface temperatures of most generators during reentry trajectories having reentry angles less than 10 degrees. The second is a parametric method of finding the temperature effects of thermal resistance between the fuel and the case. This method applies to operating and reentry temperatures.

Reference 12 gives radiation equilibrium temperatures for free molecule and continuum flow as functions of altitude, velocity, heating ratio, and emissivity. Generally, the radiation equilibrium temperature is an accurate approximation of a vehicle's surface temperature during reentry only if the vehicle has a low heat capacity and a slowly changing heat input. However, the internal generation of a nuclear power supply partially compensates for the internal heat capacitance of the generator. Furthermore, some parts of generator cases are thin and are not in good thermal contact with the interior parts of generators. These characteristics make it possible to use the curves in Reference 12 to accurately predict the case failure altitudes for shallow reentries. Taking the intact SNAP-19 as an example, the case temperature predicted by Reference 12 at the time of case failure was only $14^{\circ} \mathrm{F}$ higher than that predicted by a three-dimensional digital computer program.

This method also gives good approximations of peak heat shield temperatures during shallow reentries provided the heat transfer paral$1 e 1$ to the surface is sma11. Comparing the results predicted by Reference 12 and those predicted by a three-dimensional ablation and heat transfer computer program, there was a $45^{\circ} \mathrm{F}$ difference in the peak heat shield temperature predicted for the intact SNAP-19 heat shield during orbital decay and a $65^{\circ} \mathrm{F}$ difference during a -2.02 degree guidance failure abort. Experience with similar structures and trajectories will make it possible to estimate temperatures with increased accuracy.

Details of the uses and limitations of radiation equilibrium temperatures during reentry are given in Reference 12. Generally, this method is most useful for preliminary predictions of generator disassembly, melting of low heat capacity external components and brackets, and peak temperatures of heat shields during shallow reentries. This time saving method makes it possible to analyze more design possibilities and to find trouble areas earlier in the design. 
The thermal resistance between the fuel and the generator case has a large effect on the fuel and capsule temperatures during operation and reentry. During steady-state operation of the generator, the temperature of all components inboard of the resistance increases with increasing resistance. However, a high thermal resistance protects internal components during reentry when external aerodynamic heating rates exceed the internal generation rate.

The thermal barriers in a generator consist of containers, liners, structural members, and the energy conversion unit. Liners and containers usually have low heat capacity and low thermal resistance. Most of the resistance in these areas is between the containers where heat is transferred by radiation and/or conduction through gases. Restricting digital computer programs to the conventional nodal approach in these areas requires an excessive amount of setup and machine time. Whenever the heat capacity of the multiple containers can be neglected (steady-state or low heat capacity structures with slowly changing temperatures), heat transfer can be treated as a single radiation path in parallel with a single conduction path. Multiple containers act as radiation shields, and the multiple series radiation paths can be handled with a single expression using an effective radiation interchange factor. Methods of computing and using effective radiation interchange factors for radiation shields are given in Appendix A. Conduction through the multiple gas layers in series can be handled with a single conduction equation provided the partitions have a relatively low resistance. The conduction distance in this equation would be the sum of the individual gas layer thicknesses. The fourth power temperature dependence of radiation and the linear dependence of conduction do not curtail accuracy in the temperature ranges of most generators.

Often it is more convenient to conduct a parametric study, varying the effective radiation interchange factor and/or conductance, than to analyze each design alternative. The results of a parametric study of this type are shown in Figure 9. The temperature curves in Figure 9 are for steady-state operation in space, but the same method can be applied to maximum temperatures during reentry. The following information can be read directly from the curves:

1. Capsule temperatures for each container design can be found by simply computing the effective radiation interchange factors for each design.

2. The interchange factor which corresponds to the maximum allowable capsule temperature can be found. This was the method used to determine the maximum number of heat shields that could be used in the intact SNAP-19 heat source. 9

3. The change in temperature with loss of pressure is given for a11 interchange factors. 


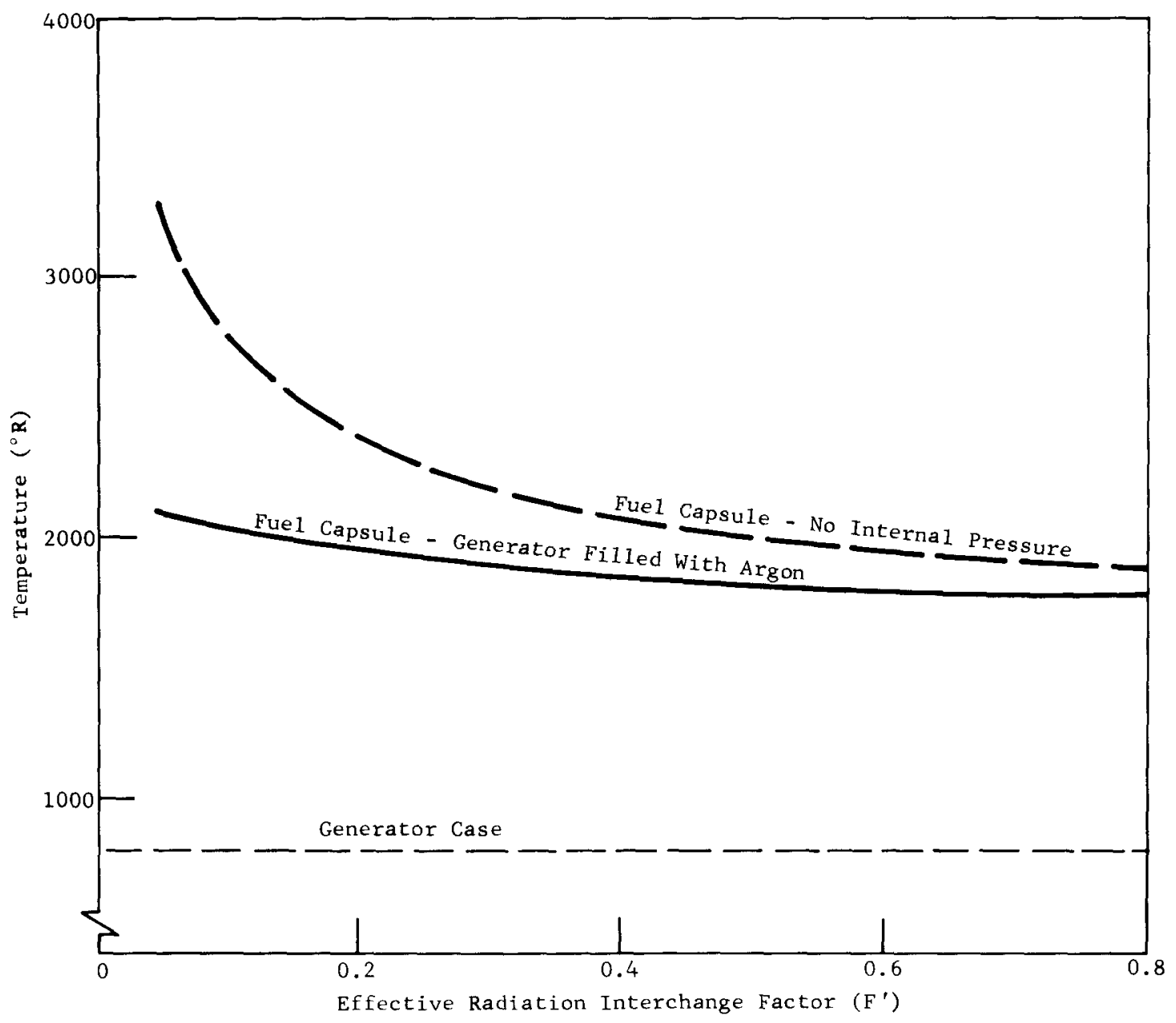

Figure 9. Typical generator temperatures in space as a function of the radiation interchange factor between the case and fuel capsule (D68-11452) 
APPENDIX A

Thermal Radiation Shields 
Blank Page 
APPENDIX A

Therma1 Radiation Shields

When a shield is placed between two radiating surfaces, the rate of heat transmission due to radiation is greatly reduced if the temperatures of the surfaces are unchanged; the temperature difference between the two surfaces will increase if the heat transmission is constant. Heat shields are common in nuclear power supplies. They are used to block heat transfer intentionally in some locations by the use of either multifoil insulation or single metallic shields. In other cases, heat shields are undesirable but necessary deterrents to heat transfer. Containers, liners, and structural members between the heat source and cooling fins are examples of the later classification. It is often convenient to determine the effect of heat shields without going through a complete thermal analysis. This can be accomplished by using an effective radiation interchange factor ( $F^{\prime}$ ) between the heat source and heat sink. The only restriction is that the shields must have a relatively low heat capacity when applied to transient analyses.

fer is:

Assuming the configurations in Figure $A-1$, the radiant heat trans-

$$
\mathrm{Q}=\sigma \mathrm{A}_{1} \mathrm{~F}_{1-2} \cdot\left(\mathrm{T}_{1}^{4}-\mathrm{T}_{2}^{4}\right)
$$

where

$$
\begin{aligned}
F & =\mathrm{f}\left(\mathrm{F}_{\epsilon}, \mathrm{F}_{\mathrm{A}}\right) \text {, radiation interchange factor } \\
\mathrm{F}_{\epsilon} & =\text { Emissivity factor } \\
\mathrm{F}_{\mathrm{A}} & =\text { Area factor } \\
\sigma & =\text { Stephan Boltzman constant. }
\end{aligned}
$$
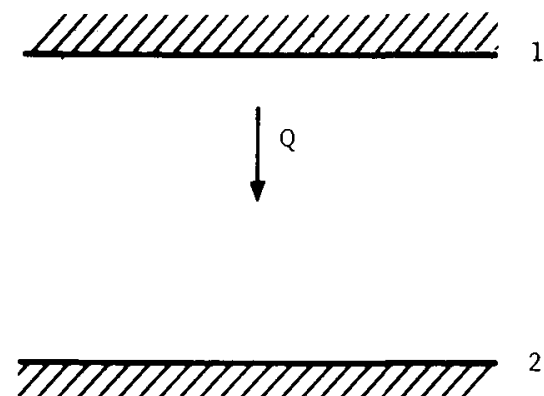

Unshielded Configuration
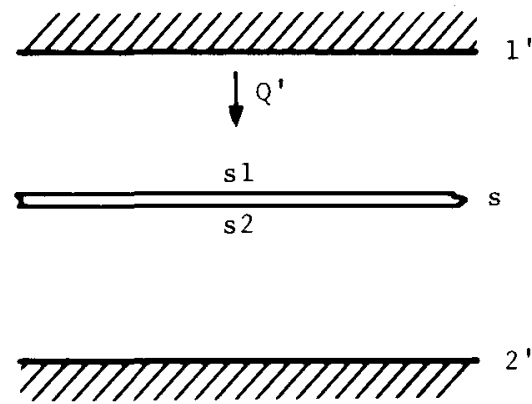

Shielded Configuration

Figure A-1. Radiation shields (D68-11453) 


\section{Effective Interchange Factor}

The following is a derivation of an effective interchange factor $F_{1-2}^{\prime}$ between surfaces $1^{\prime}$ and $2^{\prime}$. To find an effective $F$, it is necessary to assume that $Q, T_{1}$, and $\dot{T}_{2}$ are the same for the shielded and unshielded configuration.'

For a unit area :

$$
\mathrm{Q}=\sigma \mathrm{F}_{1-2}\left(\mathrm{~T}_{1}^{4}-\mathrm{T}_{2}^{4}\right)=\sigma \mathrm{F}_{1}^{\prime}-\mathrm{s} 1\left(\mathrm{~T}_{1}^{4},-\mathrm{T}_{\mathrm{s}}^{4}\right)=\sigma \mathrm{F}_{\mathrm{s} 2-2^{\prime}}\left(\mathrm{T}_{\mathrm{s}}^{4}-\mathrm{T}_{2}^{4}{ }^{\prime}\right)
$$

then

$$
\begin{aligned}
& \mathrm{T}_{1}^{4}=\frac{\mathrm{Q}}{\sigma \mathrm{F}_{1-2}}+\mathrm{T}_{2}^{4} \\
& \mathrm{~T}_{1^{\prime}}^{4}=\frac{\mathrm{Q}}{\sigma \mathrm{F}_{1^{\prime}-\mathrm{s} 1}}+\mathrm{T}_{\mathrm{s}}^{4} \\
& \mathrm{~T}_{\mathrm{S}}^{4}=\frac{\mathrm{Q}}{\sigma \mathrm{F}_{\mathrm{s} 2-2^{\prime}}}+\mathrm{T}_{2^{\prime}}^{4}
\end{aligned}
$$

Combining Eqs. $(\mathrm{A}-3)$ and $(\mathrm{A}-4)$

$$
\mathrm{T}_{1^{\prime}}^{4}=\frac{\mathrm{Q}}{\sigma}\left(\frac{1}{\mathrm{~F}_{\mathrm{s} 2-2^{\prime}}}+\frac{1}{\mathrm{~F}_{1^{\prime}-\mathrm{s} 1}}\right)+\mathrm{T}_{2^{\prime}}^{4} \cdot
$$

Equating Eqs. $(A-2)$ and $(A-5)$

$$
\frac{1}{F_{1-2}}=\frac{1}{F_{1^{\prime}-s 1}}+\frac{1}{F_{s 2-2^{\prime}}}
$$

Then the equivalent $F$ for computing the radiant heat transfer between surfaces 1 and 2 separated by a heat shield is:

$$
F_{1-2}^{\prime}=\frac{1}{\frac{1}{F_{1^{\prime}-s 1}}+\frac{1}{F_{s 2-2^{\prime}}}} .
$$


When there are multiple radiation shields, the equivalent $F$ is

$$
F_{1-2}^{\prime}=\frac{1}{\frac{1}{F_{1^{\prime}-s 1}}+\frac{1}{F_{s 2-s 3}}+\cdots+\frac{1}{F_{s i-2}}}
$$

where sl to si are the surfaces of the heat shields.

If the interchange factors are all the same, Eq. (A-8) becomes

$$
F_{1-2}^{\prime}=\frac{F_{1}^{\prime}-s 1}{n+1}
$$

where $\mathrm{n}$ is the number of radiation shields.

When the distances between radiating surfaces are small compared to their areas or when surfaces of outer concentric spheres or semiinfinite coaxial cylinders are specularly reflective, the interchange factor is

$$
F=\frac{1}{\frac{1}{\epsilon_{1}}+\frac{1}{\epsilon_{2}}-1}
$$

Whenever $\mathrm{Eq} .(\mathrm{A}-10)$ holds, the effective interchange factor is

$$
F^{\prime}=\frac{1}{\frac{1}{\epsilon_{1}}+\frac{1}{\epsilon_{2}}+\cdot \cdot+\frac{1}{\epsilon_{\mathrm{m}}}-\frac{\mathrm{m}}{2}}
$$

where $m=2(n+1)$ is the number of radiating surfaces.

For concentric spheres and semi-infinite coaxial cylinders with diffusely reflecting surfaces, the interchange factor is 13

$$
F_{1-2}=\frac{1}{\frac{1}{\epsilon_{1}}+\frac{A_{1}}{A_{2}}\left(\frac{1}{\epsilon_{2}}-1\right)}
$$

where the subscript 1 refers to the inner body and $A$ is the surface area. 
Whenever Eq. (A-11) cannot be used because of large area differences between diffusely reflecting surfaces, Eq. (A-12) must be used in conjunction with Eq. (A-8) to find the effective interchange factor with radiation shields present. Whenever the distance between coaxial cylinders is too large compared to the cylinder lengths to use the semi-infinite approximation, the area factor $\left(F_{A}\right)$ and emissivity factor $\left(\mathrm{F}_{\epsilon}\right)$ can be used to compute the interchange factor (see Appendix $\mathrm{B}$ ).

\section{Fixed Heat Flux}

In space nuclear power supplies, the heat flux and cold side temperature are usually fixed. Under these conditions, the insertion of heat shields will raise the temperature of the fuel capsule. The effect of heat shields on the hot side temperature can be found by combining Eqs. $(A-2)$ and $(A-5)$ and expanding for multiple shields.

$$
\mathrm{T}_{1}^{\prime}=\left[\mathrm{T}_{1}^{4}+\frac{\mathrm{Q}}{\sigma}\left(\frac{1}{\mathrm{~F}_{1^{\prime}-\mathrm{s} 1}}+\frac{1}{\mathrm{~F}_{\mathrm{s} 1-\mathrm{s} 2}}+\cdots \cdot+\frac{1}{\mathrm{~F}_{\mathrm{si-2}}}-\frac{1}{\mathrm{~F}_{1-2}}\right)\right]^{1 / 4} \cdot
$$

Similarly, if the heat $f 1 u x$ and hot side temperature are fixed, the cold side temperature with heat shields is:

$$
\mathrm{T}_{2}^{\prime}=\left[\mathrm{T}_{2}^{4}-\frac{\mathrm{Q}}{\sigma}\left(\frac{1}{\mathrm{~F}_{1^{\prime}-\mathrm{s} I}}+\frac{1}{F_{\mathrm{s} I-\mathrm{s} 2}}+\cdots \cdot+\frac{1}{\mathrm{~F}_{\mathrm{s} i-2^{\prime}}}-\frac{1}{\mathrm{~F}_{1-2}}\right)\right]^{1 / 4} \cdot(\mathrm{A}-14)
$$

\section{Fixed Temperatures}

When radiation shields are used 1ocally, they may not change the hot and cold wall temperatures significantly, but they will reduce local heat losses. The effect of heat shields on heat transmission can be found as follows (refer to Figure A-1):

$$
\begin{aligned}
& Q^{\prime}=\sigma F_{1}{ }_{1-s 1}\left(T_{1}^{4}-T_{s}^{4}\right) \\
& Q^{\prime}=\sigma F_{s 2-2} \cdot\left(T_{s}^{4}-T_{2}^{4}\right) .
\end{aligned}
$$

Combining Eqs. $(A-15)$ and $(A-16)$

$$
\mathrm{T}_{\mathrm{s}}^{4}=\frac{1}{\mathrm{~F}_{1^{\prime}-\mathrm{s} 1}+\mathrm{F}_{\mathrm{s} 2-2^{\prime}}}\left(\mathrm{F}_{1^{\prime}-\mathrm{s} 1} \mathrm{~T}_{1}^{4}+\mathrm{F}_{\mathrm{s} 2-2^{\prime}} \mathrm{T}_{2}^{4}\right)
$$


Substituting Eq. (A-17) into Eq. (A-15)

$$
Q^{\prime}=\sigma \frac{F_{1^{\prime}-s 1} F_{s 2-2^{\prime}}}{F_{1^{\prime}-s 1}+F_{s 2-2}}\left(T_{1}^{4}-T_{2}^{4}\right) .
$$

Equating Eq. (A-1) to Eq. (A-18)

$$
Q^{\prime}=Q \frac{F_{1}-s 1 F_{s 2-2^{\prime}}}{F_{1-2}\left(F_{1^{\prime}-s 1}+F_{s 2-2^{\prime}}\right)} .
$$

If all the interaction factors are identical, Reference 14 showed that

$$
Q^{\prime}=\frac{1}{n+1} Q
$$

where $\mathrm{n}$ is the number of heat shields. 
Blank Page 


\section{APPENDIX B}

Radiation Area Factors

For Coaxial Cylinders of Finite Length 
Blank Page 


\section{Radiation Area Factors \\ For Coaxial Cylinders of Finite Length}

Whenever coaxial cylinders or cylinder segments are short enough to allow a significant amount of radiation loss from the ends, Eqs. $(A-10)$ and $(A-12)$ are not valid. Area factors (also called view factor, angle factor, configuration factor, or form factor) for combinations of discs, finite length cylinders, finite length annuli, and planes are given in Reference 15. The area factor is defined as the fraction of the total radiation leaving one surface which intercepts the other surface. This definition also holds for the radiation leaving one part of a surface that intercepts other parts of the same surface. Area factors are functions of the shapes and relative positions of the two surfaces and are governed by the cosine law and the inverse square law of radiation intensity.

of particular interest in isotopic power supplies is the area factors for coaxial cylinders (Figure B-1). Figure B-2, taken from Reference 15, gives area factors in graphical form for the configuration of Figure $B-1$.

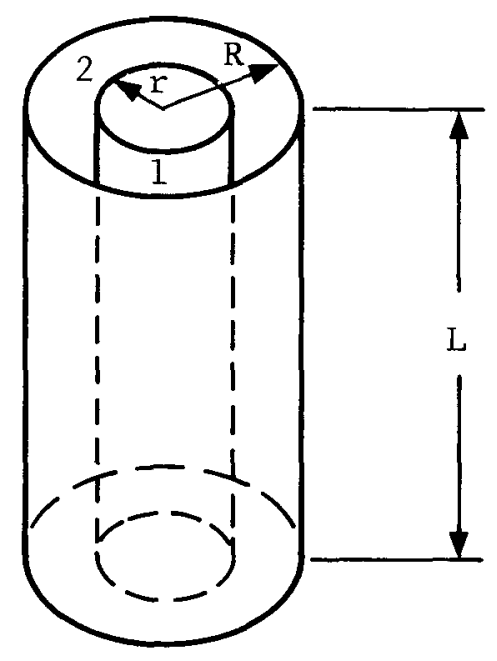

Figure $B-1$.

Equal length coaxial cylinders $($ D68-11454) 
Outer Cylinder to Inner Cylinder

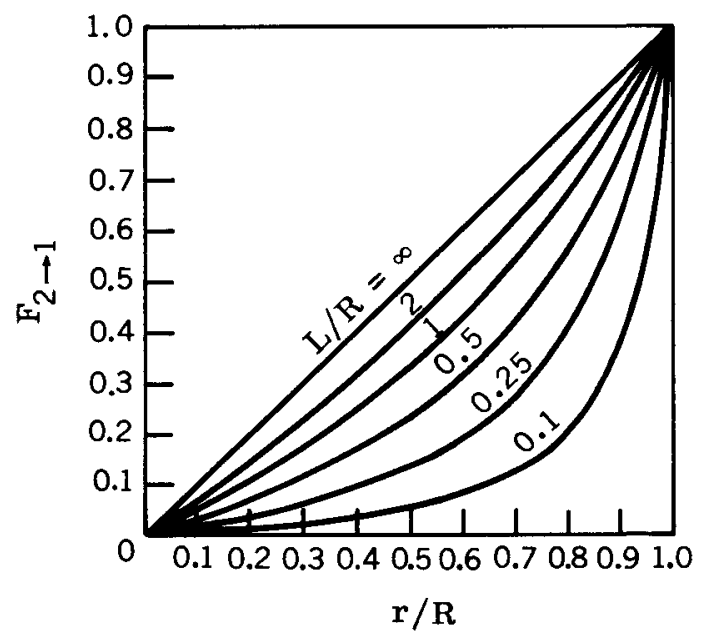

Outer Cylinder to Itself

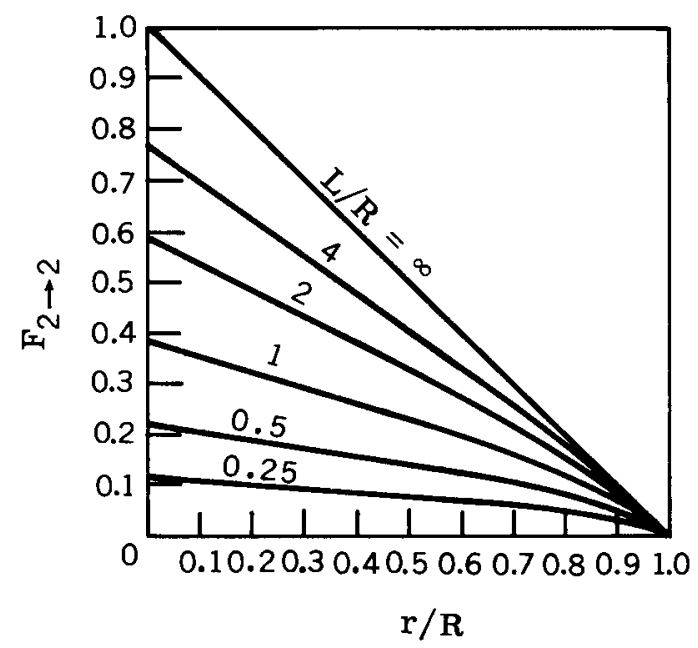

Figure B-2. Area factors for coaxial cylinders of equal length, one inside the other (D68-11455)

Whenever there is a longitudinal as well as a radial temperature gradient, it is necessary to divide each cylinder into several nodes to perform an accurate thermal analysis. By the use of area factor algebra, the factors in Figure B-2 can be used to compute area factors for offset coaxial cylinders. Referring to the nomenclature in Figure $\mathrm{B}-3$, the area factors for offset coaxial cylinders are as follows:

\section{Outer cylinder to itself}

$$
\mathrm{F}_{1 \rightarrow 2}=\frac{1}{\mathrm{~A}_{1}}\left(\mathrm{~A}_{1+2} \mathrm{~F}_{1+2 \rightarrow 1+2}-\mathrm{A}_{1} \mathrm{~F}_{1 \rightarrow 1}-\mathrm{A}_{2} \mathrm{~F}_{2 \rightarrow 2}-\mathrm{A}_{2} \mathrm{~F}_{2 \rightarrow 1}\right) \text {. }
$$

If $\mathrm{L}_{1}=\mathrm{L}_{2}$,

$$
\mathrm{F}_{1 \rightarrow 2}=\mathrm{F}_{1+2 \rightarrow 1+2}-\mathrm{F}_{1 \rightarrow 1}
$$

Outer cylinder to inner cylinder

$$
\mathrm{F}_{1 \rightarrow 4}=\frac{1}{\mathrm{~A}_{1}}\left(\mathrm{~A}_{1+2} \mathrm{~F}_{1+2 \rightarrow 3+4}-\mathrm{A}_{1} \mathrm{~F}_{1 \rightarrow 3}-\mathrm{A}_{2} \mathrm{~F}_{2 \rightarrow 4}-\mathrm{A}_{2} \mathrm{~F}_{2 \rightarrow 3}\right) .
$$

If $\mathrm{L}_{1}=\mathrm{L}_{2}$,

$$
\mathrm{F}_{1 \rightarrow 4}=\mathrm{F}_{1+2 \rightarrow 3+4}-\mathrm{F}_{1 \rightarrow 3} .
$$




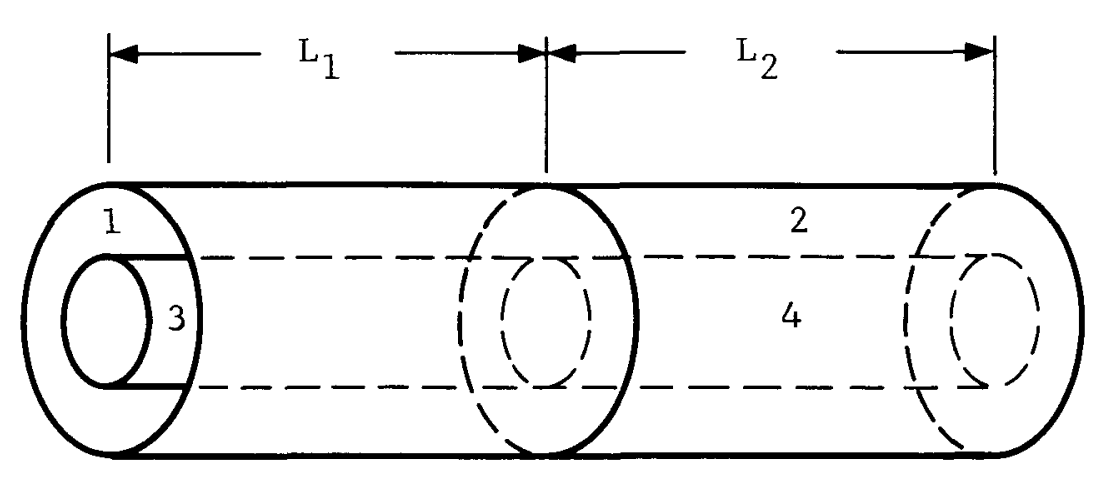

Figure B-3. Offset coaxial cylinders (D68-11456) 


\section{References}

1. Klett, R. D., Reentry Therma1 Analysis of the SNAP-19/NimbusB/ Agena System, SC-RR-66-2672, Sandia Laboratory, Albuquerque, New Mexico, March 1967.

2. Randa11, D. E., Aerotherma1 Analysis of the SNAP-19 (Dispersa1 Capsule Design) Aboard the Agena/Nimbus B Spacecraft (U), SC-RR-68-96, Sandia Laboratory, Albuquerque, New Mexico, to be published (CRD).

3. Klett, R. D., Thermal Design of a SNAP-19 Generator for Intact Reentry (U), SC-RR-67-197, Sandia Laboratory, Albuquerque, New Mexico, May 1967 (CRD).

4. Memo, Berry, R. E., 9312, to Jeffers, S. L., 9312, Helium Pressure Within the SNAP-19 IRHS During Atmospheric Reentry, dated February 8, 1968.

5. Merrill, G., Missile Engineering Handbook, D. Van Nostrand, New York, 1958.

6. Taylor, L., Metals Handbook, Vo1. 1, American Society for Metals, Metals Park, Ohio, 1961.

7. Weiss, V., Aerospace Structural Metals Handbook, Vol. II, Syracuse University Press, 1963.

8. Kite, F. D., and Bader, B. E., Pad-Abort Thermal Flux Model for Liquid Rocket Propellants, SC-RR-66-577, Sandia Laboratory, Albuquerque, New Mexico, November 1966.

9. Klett, R. D., Therma1 Analysis of the Intact SNAP-19/Nimbus B/ Agena System (U) , SC-RR-68-95, Sandia Laboratory, Albuquerque, New Mexico, to be published (CRD).

10. Proceedings of Asset/Advanced Lifting Reentry Technology SympoSium (U), AFFDL-TR-66-22, March 1966 (CDI).

11. Marnoch, K., High Temperature Oxidation Resistant HafniumTantalum Systems, AFML-TR-65-240, JuIy 1965.

12. Klett, R. D., Reentry Temperatures of Low Heat Capacity Structures, SC-RR-67-232, Sandia Laboratory, Albuquerque, New Mexico, August 1967.

13. Christiansen, C., Wiedemanns Ann. (19), 267, 1883.

14. Wiener, 0., Ann. Physik (4) 60, 324, 1919.

15. Leuenberger and Person, Compilation of Radiation Shape Factors for Cylindrical Assemblies, ASME paper No. 56-A-144, 1956. 
DISTRIBUTION :

TID-4500 (51st Ed.) UC-36

U. S. Atomic Energy Commission Division of Space Nuclear Systems Space Electric Power Office

Washington, D.C. 20545

Attn: G. A. Newby Assistant Director (1)

G. P. Dix Chief, Safety Branch (1)

R. S. Decker, Jr. Chief, Safety Branch

R. T. Carpenter, Chief Isotope Power' Systems $\mathrm{Br}$. (1)

J. A. Powers, Chief Isotope Power Systems Br. (1)

C. Johnson, Chief Reactor Systems Branch

U. S. Atomic Energy Commission Division of Isotope Development Washington, D.C. 20545

U. S. Atomic Energy Commission Director of Regulation Washington, D.C. 20545 Attn: C. K. Beck Deputy Director

F. D. Anderson Regulation (1)

U. S. Atomic Energy Commission Division of Biology and Medicine Washington, D.C. 20545

Attn: J. Z. Holland, Chief Fallout Studies Branch (1)

H. D. Bruner, Asst. Dir. Med. and Health Research (1)

U. S. Atomic Energy Commission Space Nuclear Propulsion Office Albuquerque Extension Albuquerque Operations office P.O. Box 5400

Albuquerque, New Mexico 87115

Attn: H. P. Smith

U. S. Atomic Energy Commission Albuquerque Operations Office P.O. Box 5400

Albuquerque, New Mexico 87115

Attn: S. A. Upson, Director Non-Nuclear Activities Div.

J. F. Burke, Director Operational Safety Div.
U. S. Atomic Energy Commission

Site Representative

Nationa1 Aeronautics and Space Adm. Manned Spacecraft Center

Houston, Texas 77058

Attn: W. C. Remini

BIdg. 16, Code ZS-5

Donald W. Douglas Laboratories

P.0. Box 310

Richland, Washington 99352

Attn: S. P. Gydesen

Douglas Aircraft Company

Missile \& Space Systems Division

3000 Ocean Park Blvd.

Santa Monica, California

Attn: Sig Gronich Adv. Space Technology

General Electric Company

Valley Forge Space Technology Ctr. P.O. Box 8555

Philadelphia, Pennsylvania 19101

Attn: S. M. Scala, Room M9539 Space Sciences Lab (1)

G. W. Rivenbark, Isotope Power Sys. Opr.

Deputy I. G. for Insp. and Safety USAF, Kirtland Air Force Base New Mexico 87117

Attn: Col. D. C. Jameson (AFINSR)

Los Alamos Scientific Laboratory P.O. Box 1663

Los Alamos, New Mexico 87544

Attn: Dr. L. D. P. King (1)

Dr. Wright Langham (1)

C. F. Metz, CMB-1 (1)

F. W. Schonfeld, CMF-5

Martin-Marietta Corporation

Martin Company

Nuclear Programs

Middle River, Maryland 21203

Attn: D. Anderson

Monsanto Research Corporation Mound Laboratory

P.O. Box 32

Miamisburg, Ohio 45342

(1) Attn: G. R. Grove 


\section{DISTRIBUTION (cont):}

Thomas B. Kerr

Code RNS

National Aeronautics and Space Adm.

Washington, D.C. 20545

National Aeronautics and Space Adm. Ames Research Center

Moffet Field, California

Attn: Glenn Goodwin

U. S. Naval Radiological Defense Lab. San Francisco, California 94135

Attn: S. Z. Mikhail Nuclear Systems Group

National Aeronautics and Space Adm. Goddard Space Flight Center

Glenn Dale Road

Greenbe1t, Maryland 20771

Attn: A. W. Fihelly Nimbus Project

Naval Facilities Engineering Command Department of the Navy, Code 042

Washington, D.C. 20390

Attn: Graham Hagey

Space Nuclear Propulsion Office

Lewis Research Center

21000 Brookpark Road

C1eveland, Ohio 44135

Attn: L. Nichols

TRW Systems

P.0. Box 287

Redondo Beach, California 90278

Attn: Dr. Donald Jortner

Union Carbide Corporation

Nuclear Division

P.O. Box X

Oak Ridge, Tennessee 37831

Attn: R. A. Robins on Isotope Development Ctr. (1)

B. R. Fish

Health Physics Division (1)

U. S. Public Health Service

Nat. Ctr. for Radiological Health

1901 Chapman Avenue

Rockville, Maryland 20852

Attn: Nuclear Facilities Section

Dr. D. W. Sherwood

National Aeronautics and Space Adm. Manned Spacecraft Center (MSC-TD)

Houston, Texas 77058
J. R. Banister, 5120

J. D. Shreve, 5234

D. B. Shuster, 5600

H. E. Viney, 7130

L. E. Lamkin, 7300

G. A. Fowler, 9000

A. Y. Pope, 9300

Attn: V. E. Blake, 9310

H. E. Hansen, 9311

S. L. Jeffers, 9312

S. McAlees, Jr., 9314

R. D. Klett, 9314 (3)

R. J. Everett, 9315

J. D. Appe1, 9319

ANSIC, 9319 (2)

R. C. Maydew, 9320

A. J. C1ark, 9330

J. W. McKiernan, 9331

R. P. Stromberg, 9333

B. F. Hefley, 8232 (5)

B. R. A1len, 3421

C. H. Sproul, 3428-2 (10)

L. C. Baldwin, 3412

L. L. Alpaugh, 3412 